\title{
Investigation of the Performance of Two Passive Controllers in Mitigating the Rotational Response of Irregular Buildings
}

\author{
Yasser Bigdeli and Dookie Kim \\ Department of Civil and Environmental Engineering, Kunsan National University, Jeonbuk, Republic of Korea \\ Correspondence should be addressed to Yasser Bigdeli; yasse.bigdeli@gmail.com
}

Received 9 May 2016; Revised 21 September 2016; Accepted 22 September 2016

Academic Editor: Luigi Nicolais

Copyright ( 2016 Y. Bigdeli and D. Kim. This is an open access article distributed under the Creative Commons Attribution License, which permits unrestricted use, distribution, and reproduction in any medium, provided the original work is properly cited.

Two passive vibration control devices (i.e., circle type tuned liquid damper (C-TLD) and a circle type tuned liquid column damper (C-TLCD)) were experimentally investigated for their performance when attached to the irregular building structure subjected to dynamic loads. The specific directions where the maximum response of the structure is expected were experimentally identified for $x$ - and $y$-directions as well as for rotational direction. The power spectral density (PSD) was computed for the response of the structure based on the frequency of the first three modes and also water level changes in the device container by using fast Fourier transform (FFT). The performances of these two controllers regarding suppressing the structural vibration were compared for the seismic loads applied in an experimentally identified critical direction. The results show that these systems are effective in terms of mitigating the coupled lateral and torsional vibrations of a scaled three-story irregular model.

\section{Introduction}

In the last three decades, passive, active, and semiactive control systems were being widely used to mitigate the vibration of structures subjected to the dynamic loadings such as wind and earthquakes $[1,2]$. Various control algorithms were introduced and analytically evaluated for vibration control strategies such as sliding mode control, optimal polynomial control, neurowavelet algorithm [3], fuzzy wavelet algorithm [4], pendulum type liquid column damper (PLCD) [5], multiple tuned mass damper [6], smart passive control strategy [7], semiactive-passive strategy [8], active control strategies $[9,10]$, and electromagnetic inertial mass dampers [11]. On the other hand, classical control strategies are also included in the numerical studies such as linear quadratic regulator (LQR) feedback control [12] and linear quadratic Gaussian (LQG) algorithm which are effective when applied to the small and linearly behaving structures. The passive control systems such as a tuned mass damper, a tuned liquid damper (TLD), a tuned liquid column damper (TLCD), and tuned mass dampers (TMDs) were used to mitigate the vibrations of various structures caused by dynamic loadings [13-16]. In the tuned mass damper system a mass is attached to a building structure with a spring and a dashpot. A spring tunes structural vibration with the natural frequency of the coupled system and the dashpot dissipates the energy through the movement of the mass. Many of these devices were used and are proven to be effective in suppressing the vibrations of various structures [2]. However, there are not enough researches regarding the effectiveness of those devices in terms of decreasing the coupled horizontal and torsional vibrations of structures at the same time. Most of the experimental works were carried out on two-dimensional (2D) structures while there are a limited number of experimentally accomplished research dealing with rotational response of three-dimensional (3D) structures [17]. Furthermore, among the limited number of studies performed on 3D structures, most of them were mainly regular in the plan and height. The actual structures are not perfectly regular even though they are designed with a regular configuration. It is because of the existence of large uncertainties in the material properties used for constructing the members of the structure. Therefore, it is crucial to evaluate the control system while they are coupled with an irregular 3D building structure. In summary, the originality of this study is the irregularity of structure and rotational vibration control examinations for control devices. 

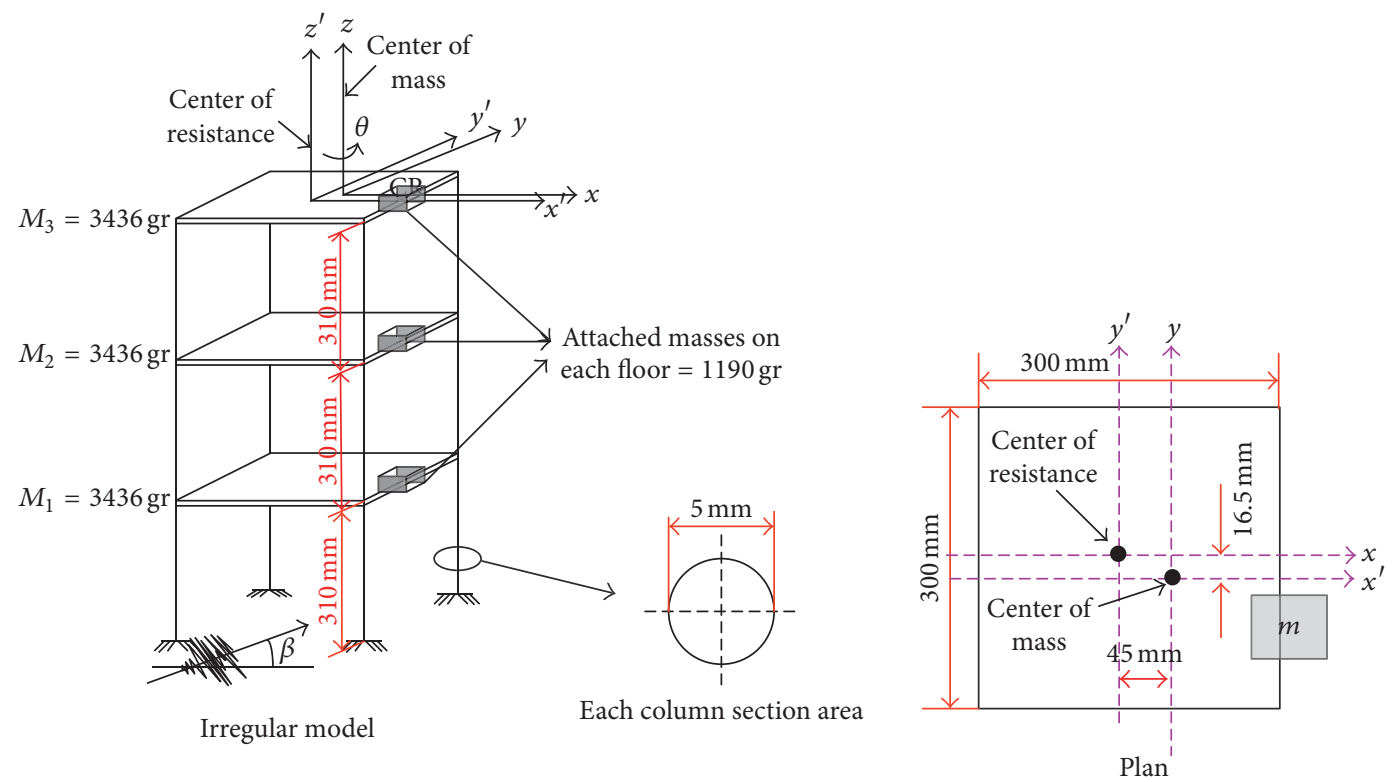

FIGURE 1: The mass and configuration details of the scaled irregular 3D three-story resisting steel frame building structure.

Additionally the effects of mass and the level of water inside the controller device are investigated in terms of mitigating the torsional response.

The performance of a tuned liquid damper depends on the motion of the liquid inside a U-shape container where an orifice is located in the center to dissipate the applied energy. Devices used in this strategy have obvious advantages over the other damping systems that are listed as follows: (1) low cost, (2) ease in terms of frequency tuning, which means ease to put it into an action, (3) usefulness for a fire extinguishing system in a building, and (4) transformative shapes which make it capable of being accommodated in a structure. In this paper, two passive devices including circle type tuned liquid column damper (C-TLCD) and circle type tuned liquid damper (C-TLD) are experimentally investigated for their performances in terms of torsional vibration mitigation of an irregular building. To do so, a scaled 3D, irregular, 3story building was used. The structure was subjected to an artificially generated excitation signal which could make the resonance effect to the uncontrolled structure. The effects of different water levels and masses were experimentally taken into account to investigate the performance of each device.

\section{Methodology}

This study is accomplished by doing the following steps: (1) setting up the building structure on a shaking table, (2) fabricating the passive controllers and installing them on the top floor, (3) defining an appropriate excitation signal, (4) importing the signal to the application program, (5) checking the accuracy of shaking table and hired accelerometers, (6) recording the structural response, and (7) interpreting the results.

2.1. Theoretical Background to Structural Response. The mechanical configuration of a simple controller used as a vibration absorber consists of a spring and a mass attached on the top of a multistory structure. In this case, dominant general equation of motion for the main structure mass and the absorber for a three-dimensional (3D) structure is as follows:

$$
\mathbf{M} \ddot{x}+\mathbf{C} \dot{x}+\mathbf{K} x=-\mathbf{M} r_{g} \ddot{x}_{g},
$$

where $\mathbf{M}, \mathbf{C}$, and $\mathbf{K}$ denote mass, damping, and stiffness matrices of the structure, respectively. $\ddot{x}, \dot{x}$, and $x$ represent the acceleration, velocity, and displacement performance of the structure, respectively. The excitation dynamic signal has been indicated by $\ddot{x}_{g}$ and $r_{g}$ defines ground influence vectors.

2.2. Structural Model. A scaled 3D 3-story moment-resisting steel frame building structure is used in this study which contains eccentricity in $x$ - and $y$-directions (i.e., $5.5 \%$ and $15 \%$ in $x$-and $y$-directions, resp.) in the plan of each floor. The total height of the structure is $930 \mathrm{~mm}$ and the natural frequency of the system is $2.86 \mathrm{~Hz}$ (see Figure 1). The diameter of the section area of each steel column is $5 \mathrm{~mm}$ and each story height is $310 \mathrm{~mm}$ for all three floors. Boundary conditions applied to the columns restricted every degree of freedom (DOF) at the base level of the building. Each floor consists of a rigid steel square plate $(300 \times 300 \mathrm{~mm})$ with a weight of 3436 gr where it contains three degrees of freedom (i.e., translation in $x$ - and $y$-directions and rotation around a vertical line passing through centers of mass) in each floor. Therefore, the total number of DOFs after application of (1) boundary conditions, (2) rigid diaphragm, and (3) Guyan reduction of vertical DOFs and rotational DOFs around $x$ and $y$-axes is equal to 9. By attaching a lumped mass of $m=1190 \mathrm{gr}(1.19 \mathrm{~kg})$ at each floor, the equal plan eccentricity of $5.5 \%$ and $15 \%$ was developed in each floor in $x$ - and $y$ directions, respectively (see Figure 1). Thus, the total weight of each floor was equal to $4626 \mathrm{gr}(4.626 \mathrm{~kg})$. Table 1 reports 


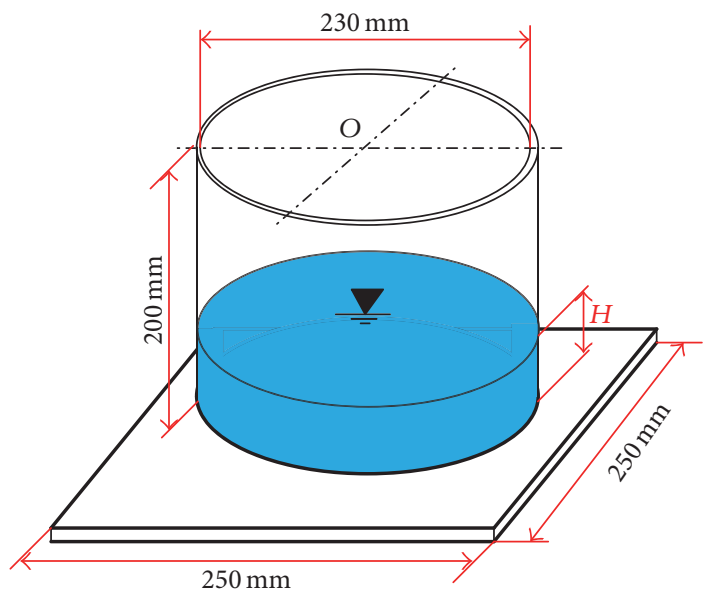

(a)

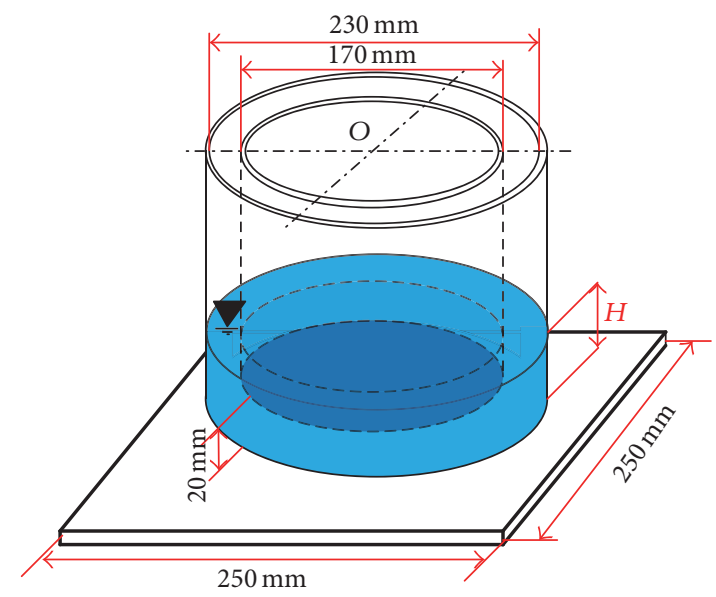

(b)

FIgure 2: Two passive vibration control systems: (a) C-TLD and (b) C-TLCD.

TABLE 1: The material properties used in constructing of the members of the model.

\begin{tabular}{lcc}
\hline Item & Value & Unit \\
\hline Young's modulus & $2 \times 10^{11}$ & $\mathrm{~Pa}$ \\
Poisson's ratio & 0.31 & - \\
Density & 7,900 & $\mathrm{~kg} / \mathrm{m}^{3}$ \\
Ultimate strength & $1.103 \times 10^{9}$ & $\mathrm{~Pa}$ \\
\hline
\end{tabular}

TABle 2: Performance properties of the employed shaking table (http://www.parkermotion.com/).

\begin{tabular}{lc}
\hline \multicolumn{2}{c}{ Performance } \\
\hline Peak force $(\mathrm{N})$ & 375.0 \\
Continuous force $(\mathrm{N})$ & 84.1 \\
Peak power $(\mathrm{W})$ & 2261 \\
Continuous power $(\mathrm{W})$ & 113 \\
Table travel $(\mathrm{cm})$ & \pm 12.0 \\
Table operational bandwidth $(\mathrm{Hz})$ & 20 \\
Table peak acceleration $(\mathrm{g})$ & 2.0 \\
\hline
\end{tabular}

the materials properties used in the fabrication of the building members.

2.3. The Passive Control Systems. Two passive control devices named C-TLD and C-TLCD were used as vibration controllers attached on the top of the building model. The properties of these systems are presented in Figure 2. Many experimental tests were performed by using the shaking table through applying the dynamic loads; and three accelerometers were attached to the structure to record the acceleration response of the building in the locations of interests. The lateral and torsional responses of the model were recorded for both controlled and uncontrolled building systems. The obtained results were used to investigate the capability of passive controllers in mitigation of torsional responses of the irregular building model.
A light type material of a fiberglass was used as a main material for fabrication of the control devices. The water level inside each container was denoted by $H$, and the center of circle base of each cylinder is denoted by $O$ throughout the paper. The water inside each device was in a direct contact with air and it could freely move if any motion was applied to the device. The properties of the C-TLD device for dimensions are shown in Figure 2(a) and the dimensional properties of the C-TLCD device are illustrated in Figure 2(b).

2.4. Building Model, Shaking Table, and Sensors. A threestory steel frame scaled building model was installed on a shaking table by using steel bolts which constrain all the DOFs of each column at base level (see Figure 3). Dynamic loading is applied to the structure by using an earthquake simulating shaking table (ST-E-1) designed by Smart Control and Sensing. The shaking table system consists of an application program, a control box, and a shaking table which are working together simultaneously and the delay time is about 62.5 microseconds which could be ignored during the process. The employed shaking table is capable of applying the excitation load in the arbitrary directions with the 10 degrees of intervals. Table 2 reports the performance characteristics of the employed shaking table. Three identical wireless accelerometers (http://www.smartcs.co.kr/) were used to record the structural response (see Figure 3). The accuracy of acceleration recorders and also the delivered excitation signal through shaking table were proved by application of a specific signal as an input signal to the application program and recording the output signal by using all three accelerometers (see Figures 4 and 5).

2.5. Excitation Signal. Figure 6(a) presents a time domain input signal selected to be applied to the model in different directions. This artificially generated signal contains the frequencies that are very close to the natural frequency of the uncontrolled system. This condition could make 


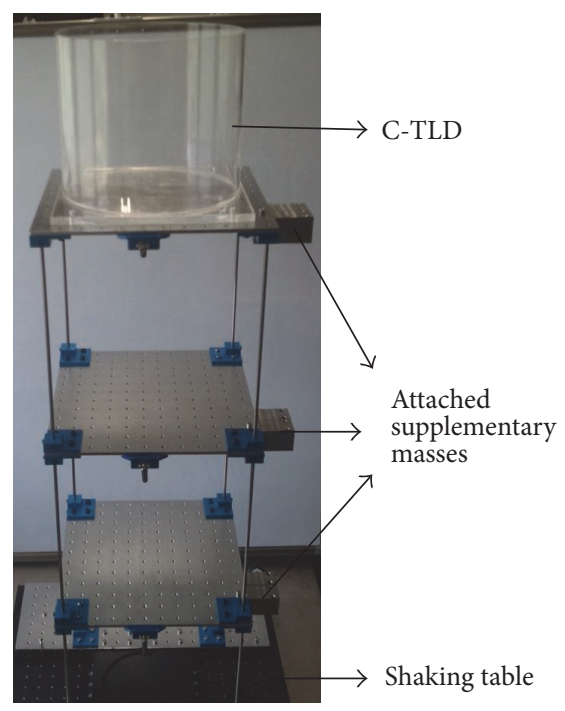

(a)

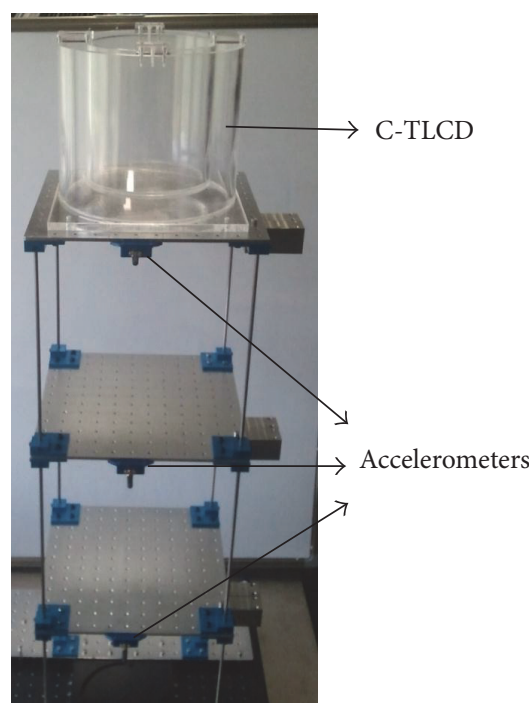

(b)

Figure 3: Experimental setup of the scaled model attached with the passive controllers on the top floor, supplementary mass, and accelerometers: (a) C-TLD and (b) C-TLCD.

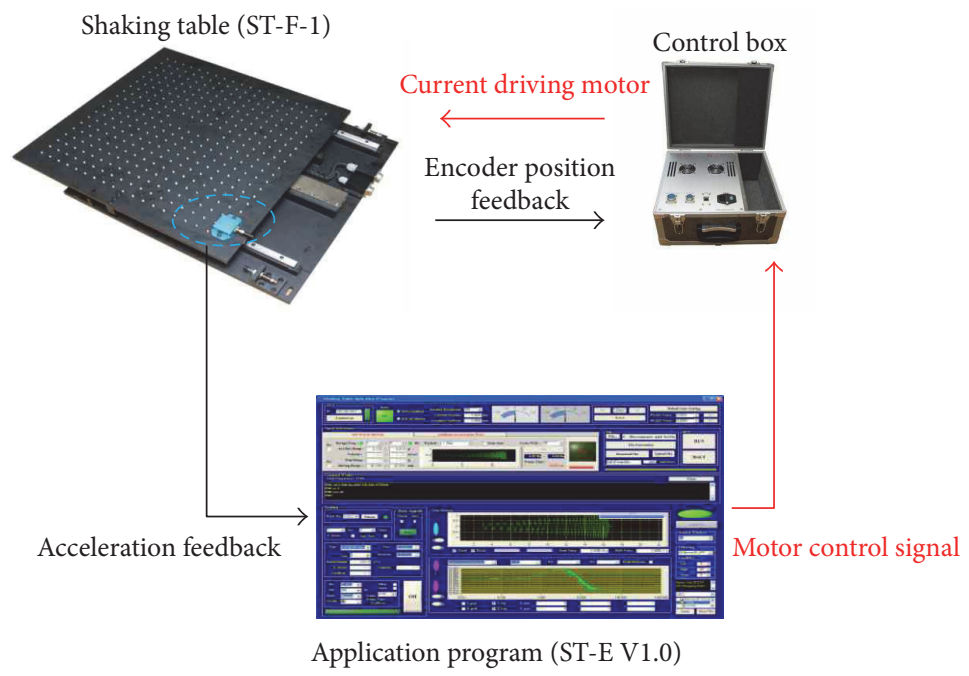

FIgURE 4: Application process of the dynamic load to the structure by using a shaking table.

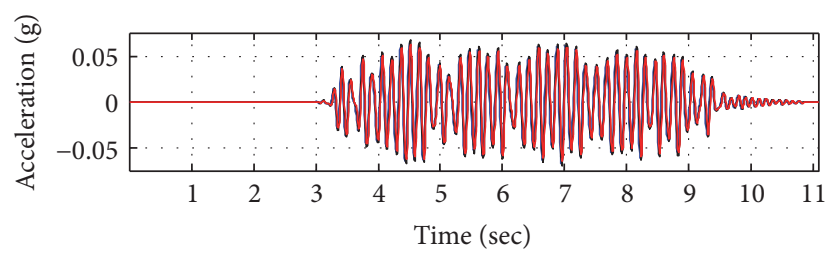

Number 1
- Number 2
Number 3

FIGURE 5: Random signal records by using three identical accelerometers to evaluate the accuracy of them. 


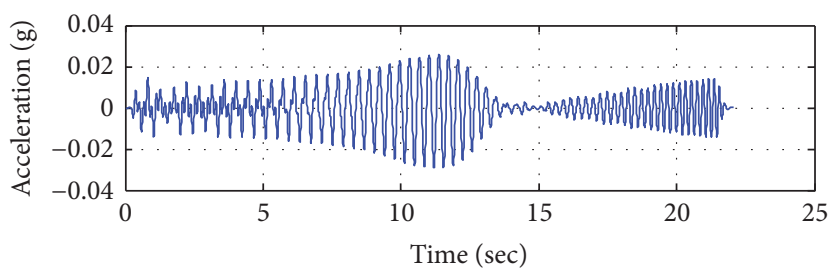

(a)

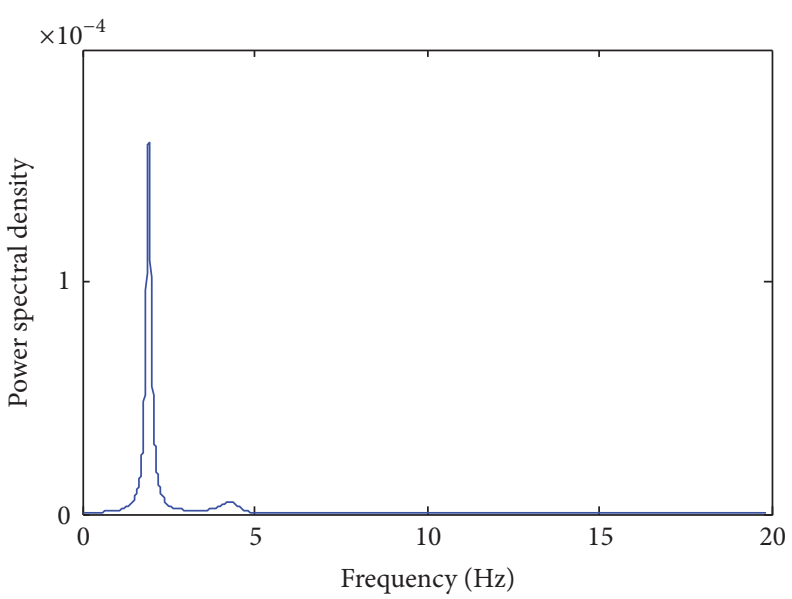

(b)

FIGURE 6: Generated artificial excitation signal: (a) time history domain representation of the signal and (b) frequency domain representation of the signal.

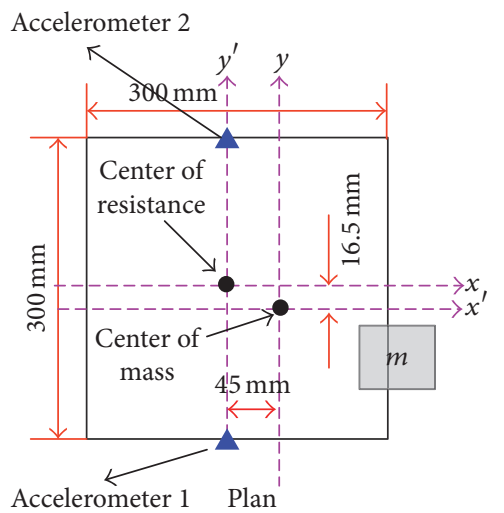

FIgURE 7: Locations of accelerometers on the top floor of the structure in order to record the relative displacement and rotational responses of the structure.

the highest impact on the building response. Figure 6(b) illustrates the frequency domain of the excitation signal where the dominant frequency (i.e., $1.92 \mathrm{~Hz}$ ) of the signal can be identified.

2.6. Control Devices' Installation. The passive control devices are installed on the top floor of the structural model as shown in Figure 3. The experimental tests were repeated for the changes in the water level inside the passive controller's container. However, the uncontrolled structural system and empty $(H=0 \mathrm{~cm}$, where $H$ represents the water level) devices also were considered in the experimental tests for a clear comparison among the results.

2.7. Acceleration Responses of the Model. In order to record the response of the building model subjected to an excitation load, three wireless accelerometers with identical properties were installed at the center of each floor. The accelerometers were equipped with a wireless Bluetooth system to transfer the data to the core computer. These devices were able to record the acceleration responses both in $x$ - and $y$-directions at the same time. The recorded data were filtered for the noise by using Butterworth LPF low pass filter, so that the obtained data were free from environmental undesired noises. In order to determine the torsional response of the third floor of the structure, a pair of accelerometers were installed in the edges of the third floor on a straight line passing through the center of geometry of the floor that are identified by two triangular shapes markers in Figure 7. Equation (2) was used to calculate the value of rotation:

$$
\theta=\frac{\left(u_{1}-u_{2}\right)}{a}
$$

in which $u_{1}$ and $u_{2}$ indicate the horizontal displacement of the edges of the top floor recorded by two sensors and $a$ represents the dimension of the floor and $\theta$ is rotation in radian. In order to find the most effective directions of a dynamic load application on the structure, the excitation signal was applied in 18 different directions with the 10 degrees of intervals. A comparison among the obtained responses of the building to the loads directions assisted 


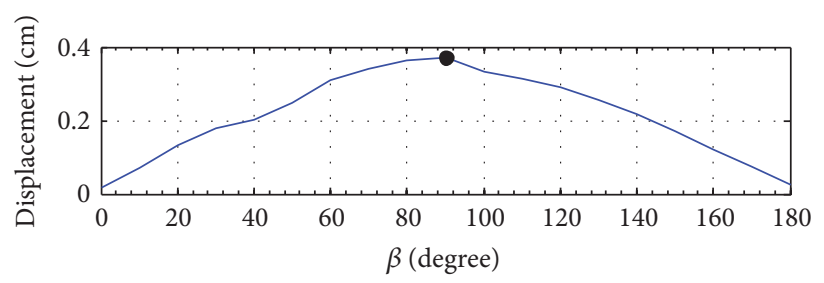

(a)

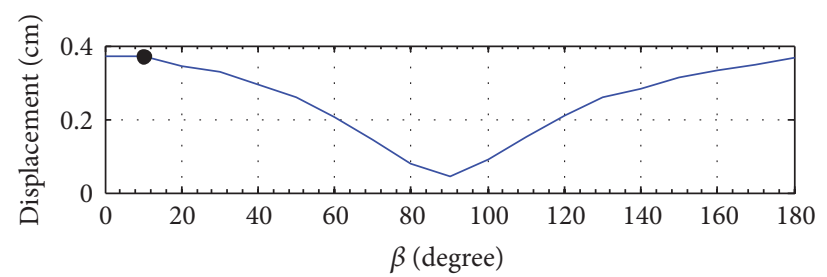

(b)

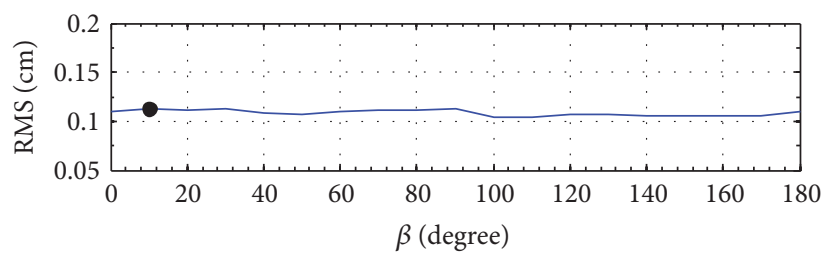

(c)

FIGURE 8: The displacement response of building model versus the angle of load application: (a) the RMS values of displacement in $x$-direction, (b) the RMS values of displacement in $y$-direction, and (c) the RMS value of the resultant displacement (bullets representing the maximum values).

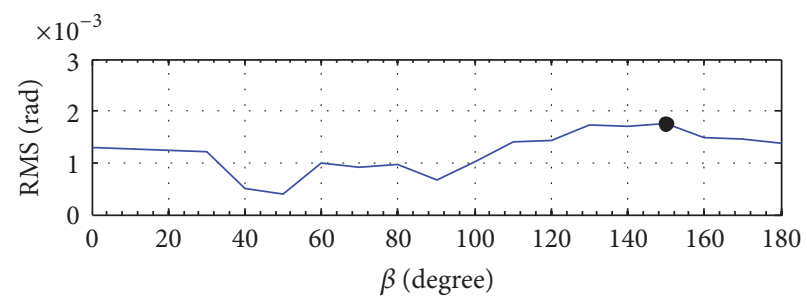

FIGURE 9: The torsional response of the building model versus the angle of dynamic excitation loading and the bullet indicates the maximum RMS value of torsion in radian unit.

to identify the most effective direction where a dynamic load should be applied for a maximized response. In the next step, the rest of the experimental studies are performed by application of the excitation load to the identified load direction.

\section{Results and Discussion}

The mass distribution in each floor of the building model is not identical, which means the centers of mass (CM) and resistance $(\mathrm{CR})$ are not located on a vertical line passing through the center of floor. Thus, the chosen building model was considered as an asymmetric building in the plan. This condition results in the coupling of lateral and torsional behaviors of the structure. In order to identify an accurate behavior of the structure subjected to dynamic loads, the lateral and torsional responses were recorded for 18 different conditions. For each condition a specific load direction was assigned. Finally, the structure was subjected to excitation loads in 18 different directions with a range of $0^{\circ}$ to $180^{\circ}$ with 10 degrees of intervals (i.e., $\beta$ measured from the positive side of the $x$-axis). Figures $8(\mathrm{a})$ and 8 (b) represent the maximum displacement of the top floor of the building versus $\beta$. The maximum displacement for the $x$ - and $y$-directions occurs at $\beta=91.2$ and 10.3 degrees, respectively (shown by a black bullet in Figures 8(a) and 8(b)). Figure 8(c) illustrates that the maximum value of Root Mean Square (RMS) values for the resultant displacements in $x$ - and $y$-directions occurs at $\beta=11$ degrees (resultant displacement $=\sqrt{u_{x}{ }^{2}+u_{y}{ }^{2}}$ ). Furthermore, the Root Mean Square (RMS) values of data were determined for the rotational response and plotted versus $\beta$ in the range of $0^{\circ}$ to $180^{\circ}$ in Figure 9. As this figure reports, the maximum torsional response occurs at $\beta=150$ degrees. As a summary of those graphs, the most 


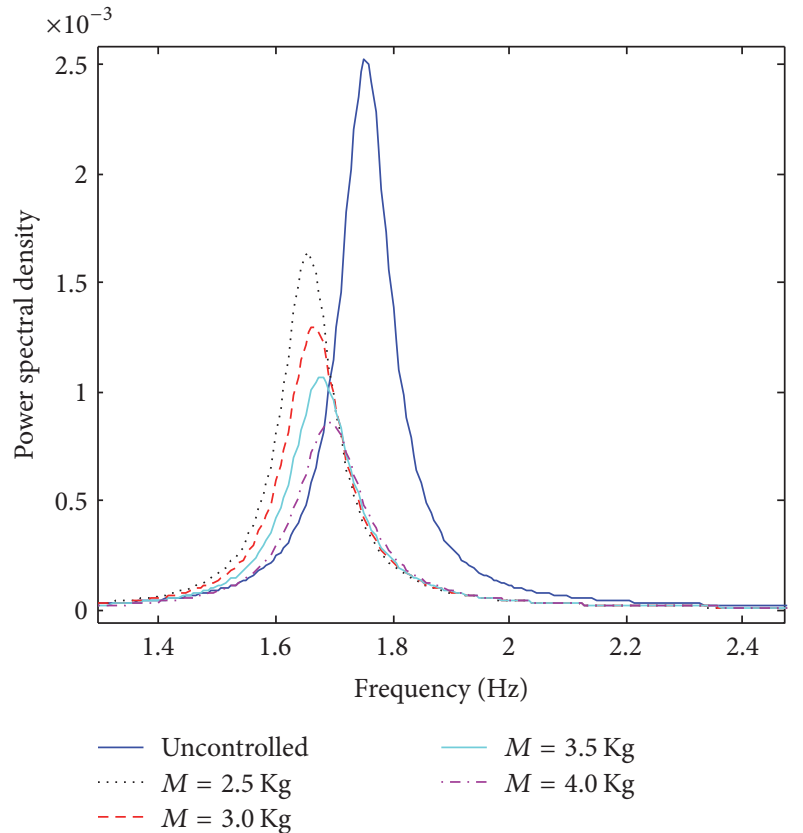

(a)

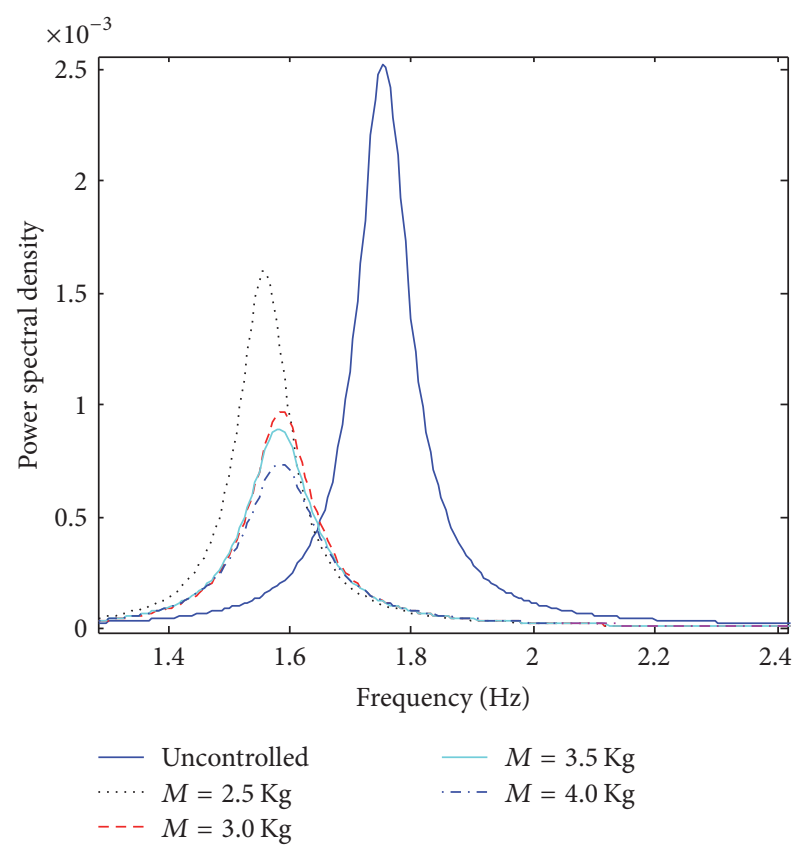

(b)

FIGURE 10: The changes in frequency domain acceleration $(\mathrm{g})$ of controlled and uncontrolled structure versus changes in total mass of passive devices. (a) C-TLD and (b) C-TLCD.

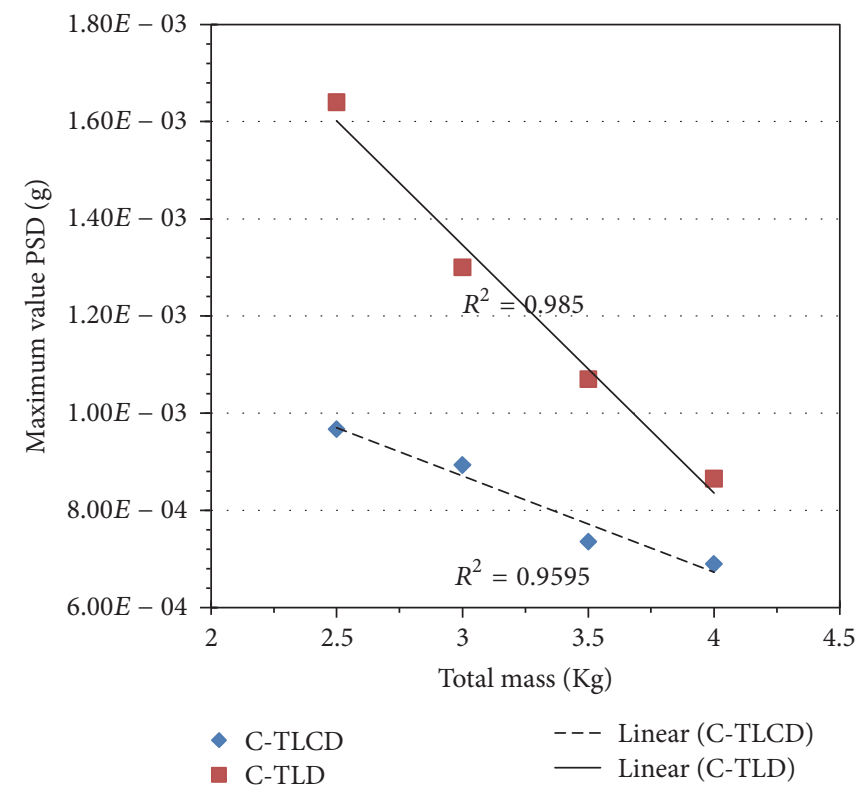

FIGURE 11: Maximum values of PSD versus total mass of water and device for C-TLD and C-TLCD passive controller.

effective angles of dynamic load application on the structure are identified as $\beta=11,91.2$, and 150 degrees measured from the positive side of the $x$-axis.

3.1. Performances of C-TLD and C-TLCD. In order to investigate the performances of the C-TLD and C-TLCD passive controllers, the power spectral density (PSD) of the response of the structure armed with a passive device was computed. The PSD values of the acceleration (in the unit of $\mathrm{g}=$ $9.81 \mathrm{~m} / \mathrm{s}^{2}$ ) response of the third floor of the structure versus frequency were developed for the different mass levels, that is, water mass plus mass of device itself (see Figure 10). Figure 10(a) presents the frequency domain response of the model for uncontrolled and controlled conditions coupled with C-TLD system. A comparison among the responses shows a significant reduction (i.e., 72\%) on acceleration response of the structure after installation of C-TLD; and it can be observed that the maximum PSD values decrease with any increase in the total mass of water and device. From graphed PSD values in Figure 10(b), it can be observed that a significant decline (i.e., 71\%) occurs in the maximum value of PSD by installation of the C-TLCD passive device on the top floor. The maximum of PSD values decreases significantly with increase in the total mass of the controllers. This can be observed from Figure 11 where trend lines with the $R$-squared values of $R^{2}=0.95$ and $R^{2}=0.98$, respectively, for C-TLCD and C-TLD are fit to the data points. It seems that the C-TLD system works more effective in terms of vibration control in comparison to C-TLCD system.

In order to investigate the effects of the different water levels for C-TLCD device, the PSD values of the displacement response of the structure were determined and plotted versus the frequency (see Figure 12). Figures 12(a) and 12(b) present the PSD values for C-TLCD-structure system in $x$ - and $y$ direction, respectively, while the system was subjected to excitation signal applied with $\beta=10^{\circ}$. These figures indicate that, by raising the water level from $H=0 \mathrm{~cm}$ to $8 \mathrm{~cm}$ in both $x$-and $y$-directions, the displacement responses of the 


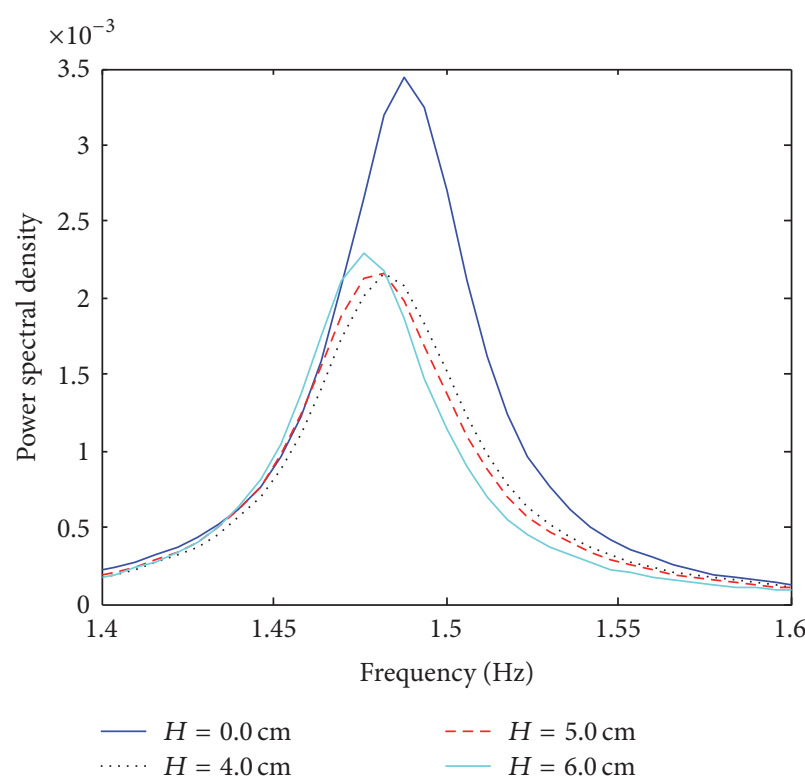

(a)

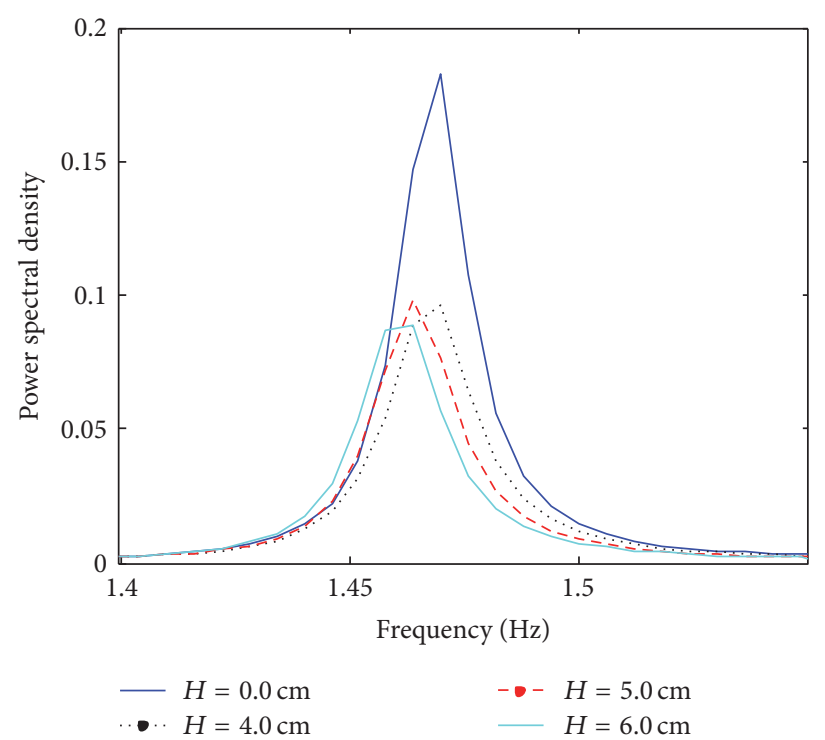

(b)

Figure 12: PSD values of displacement for the top floor of the structure when $\beta=10^{\circ}$ in both (a) $x$-direction and (b) $y$-direction.

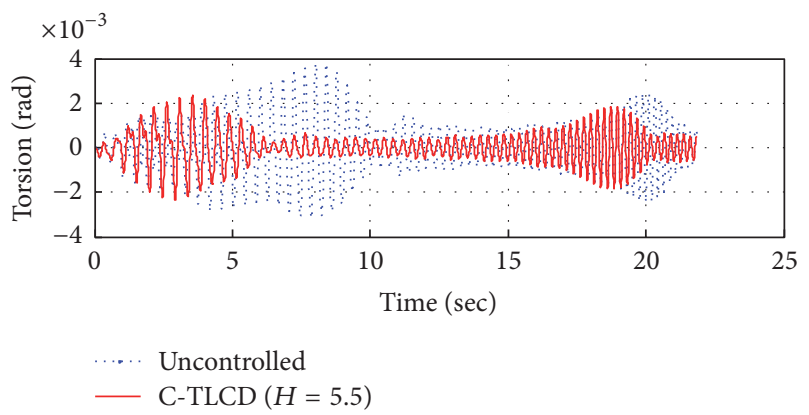

FIGURE 13: The torsional behavior of the top floor of the structure as a function of time for uncontrolled and controlled structure for $H=5.5 \mathrm{~cm}$ and $\beta=10^{\circ}$.

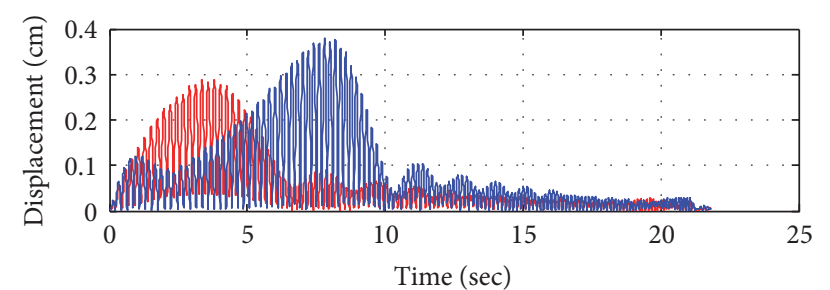

C-TLCD $(5.5 \mathrm{~cm})$

FIGURE 14: Resultant displacement of the structure in $x$ - and $y$ direction as a function of time for uncontrolled and controlled structure with C-TLCD $(H=5.5 \mathrm{~cm})$ and $\beta=10^{\circ}$.

structure were being mitigated significantly (i.e., about $43 \%$ in $x$-direction and $51.3 \%$ in $y$-direction). In fact, the C-TLCD passive controller was a promising tool in suppressing the torsional response of the building. A time history rotational

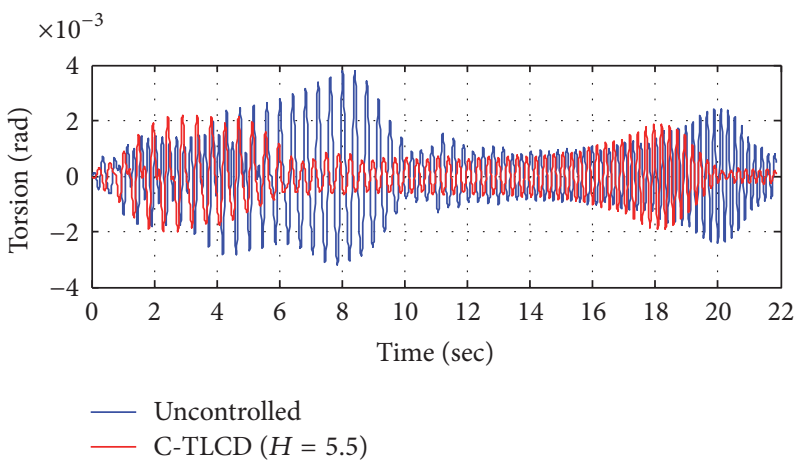

FIgURE 15: The torsional response of the structure as a function of time for uncontrolled and controlled structure for $H=5.5 \mathrm{~cm}$ and $\beta=150^{\circ}$.

response of the building is shown in Figure 13 for the controlled and uncontrolled systems where the structure was subjected to the excitation signal applied with $\beta=$ $10^{\circ}$. Figure 14 illustrates the resultant displacement response in $x$ - and $y$-direction for both controlled (C-TLCD) and uncontrolled system. Figure 15 displays torsional response of the structure subjected to excitation signal with $\beta=150^{\circ}$ for both uncontrolled and controlled structures (coupled CTLCD-structure system) as a function of time. It shows that, by attaching a passive control device on the top floor of the structure, the torsional response of the structure reduces by $50 \%$.

\section{Conclusion}

Two passive vibration control devices (i.e., circle type tuned liquid damper (C-TLD) and a circle type tuned liquid column 
damper (C-TLCD)) were experimentally tested in order to investigate the performance of these controllers on the vibration control of irregular structures. In the present study (1) an artificial excitation signal was generated for loading purposes; (2) different directions of dynamic loads were identified for the irregular model by exerting the dynamic load in 18 different directions with the interval of 10 degrees; the structure model showed the highest response for translations in $x$ - and $y$-direction at $\beta=91.2$ and 10.3 degrees, while the maximum torsional response of the building happened at $\beta=11$ degrees; (3) the effects of water level changes and total mass change for each device were tested and results showed that the lateral and torsional responses of structure could be suppressed with slight increase in the water level or the total mass; (4) it is shown that two-dimensional structural model could not present an accurate behavior of an irregular multistory buildings and it considerably underestimates the maximum response of the structure; and (5) the coupled CTLCD-structure system seems more effective in reduction of both lateral and torsional responses simultaneously.

\section{Competing Interests}

The authors declare that they have no competing interests.

\section{Acknowledgments}

This work was supported by the National Research Foundation of Korea grant funded by the Korean Government (NRF2014R1A2A1A10049538).

\section{References}

[1] N. R. Fisco and H. Adeli, "Smart structures-part I: active and semi-active control," Scientia Iranica, vol. 18, no. 3, pp. 275-284, 2011.

[2] N. R. Fisco and H. Adeli, "Smart structures: part II-hybrid control systems and control strategies," Scientia Iranica, vol. 18, no. 3, pp. 285-295, 2011.

[3] X. Jiang and H. Adeli, "Wavelet packet-autocorrelation function method for traffic flow pattern analysis," Computer-Aided Civil and Infrastructure Engineering, vol. 19, no. 5, pp. 324-337, 2004.

[4] X. Jiang and H. Adeli, "Dynamic fuzzy wavelet neuroemulator for non-linear control of irregular building structures," International Journal for Numerical Methods in Engineering, vol. 74, no. 7, pp. 1045-1066, 2008.

[5] A. Sarkar and O. T. Gudmestad, "Pendulum type liquid column damper (PLCD) for controlling vibrations of a structureTheoretical and Experimental Study," Engineering Structures, vol. 49, pp. 221-233, 2013.

[6] P. Xiang and A. Nishitani, "Seismic vibration control of building structures with multiple tuned mass damper floors integrated," Earthquake Engineering and Structural Dynamics, vol. 43, no. 6, pp. 909-925, 2014.

[7] K.-M. Choi, H.-J. Jung, H.-J. Lee, and S.-W. Cho, "Seismic protection of base-isolated building with nonlinear isolation system using smart passive control strategy," Structural Control and Health Monitoring, vol. 15, no. 5, pp. 785-796, 2008.

[8] F. Palacios-Quiñonero, J. Rubió-Massegú, J. M. Rossell, and H. R. Karimi, "Semiactive-passive structural vibration control strategy for adjacent structures under seismic excitation," Journal of the Franklin Institute, vol. 349, no. 10, pp. 3003-3026, 2012.

[9] Y. Bigdeli and D. Kim, "Active control of 3-D irregular building by using energy based neuro-controller," Advances in Structural Engineering, vol. 17, no. 6, pp. 837-849, 2014.

[10] Y. Bigdeli, D. Kim, and S. Chang, "Vibration control of 3D irregular buildings by using developed neuro-controller strategy," Structural Engineering and Mechanics, vol. 49, no. 6, pp. 687703, 2014.

[11] Y. Nakamura, A. Fukukita, K. Tamura et al., "Seismic response control using electromagnetic inertial mass dampers," Earthquake Engineering and Structural Dynamics, vol. 43, no. 4, pp. 507-527, 2014.

[12] T. T. Soong and B. F. Spencer Jr., "Active structural control: theory and practice," Journal of Engineering Mechanics, vol. 118, no. 6, pp. 1282-1285, 1992.

[13] Y. Bigdeli and D. Kim, "Response control of irregular structures using structure-TLCD coupled system under seismic excitations," KSCE Journal of Civil Engineering, vol. 19, no. 3, pp. 672681, 2015.

[14] Y. Bigdeli and D. Kim, "Damping effects of the passive control devices on structural vibration control: TMD, TLC and TLCD for varying total masses," KSCE Journal of Civil Engineering, vol. 20, no. 1, pp. 301-308, 2016.

[15] D. Kim, M. K. Hassan, S. Chang, and Y. Bigdeli, "Nonlinear vibration control of 3D irregular structures subjected to seismic loads," in Handbook of Research on Advanced Computational Techniques for Simulation-Based Engineering, p. 103, IGI Global, 2015.

[16] M. Rezaee and A. M. Aly, "Vibration control in wind turbines for performance enhancement: A Comparative Study," Wind and Structures, vol. 22, no. 1, pp. 107-131, 2016.

[17] O. Yoshida and S. J. Dyke, "Response control of full-scale irregular buildings using magnetorheological dampers," Journal of Structural Engineering, vol. 131, no. 5, pp. 734-742, 2005. 

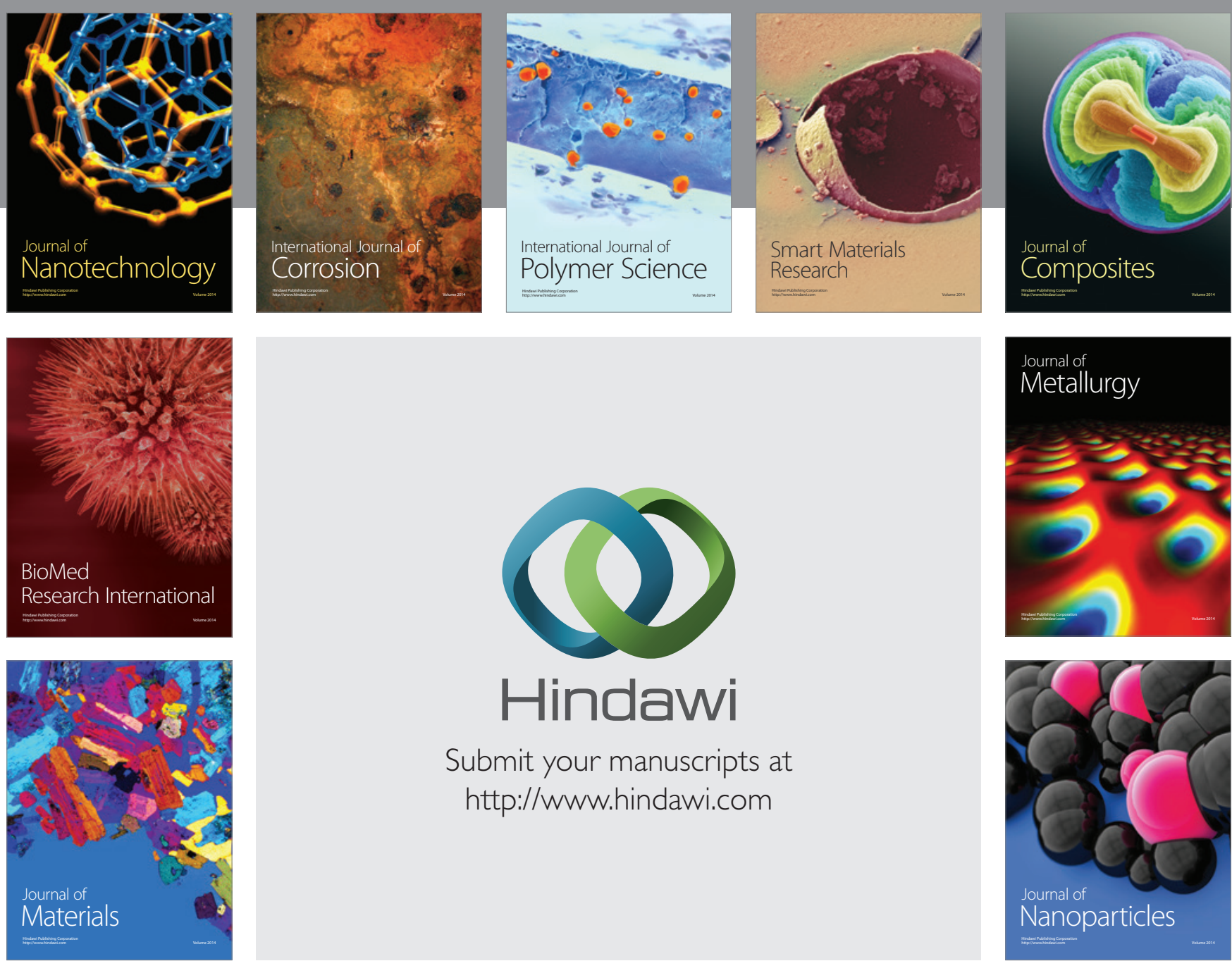

\section{Hindawi}

Submit your manuscripts at

http://www.hindawi.com

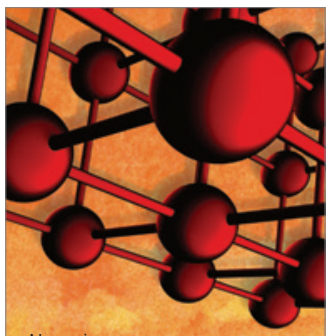

Materials Science and Engineering
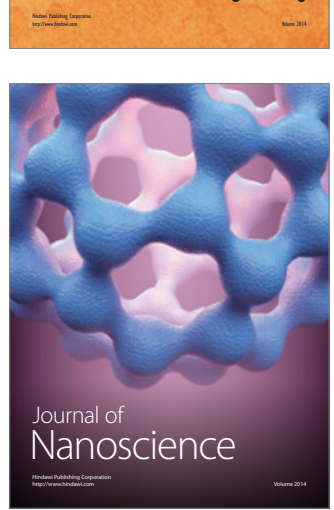
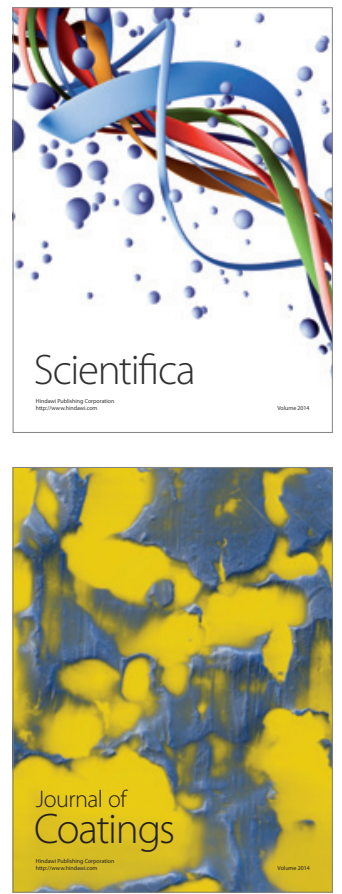
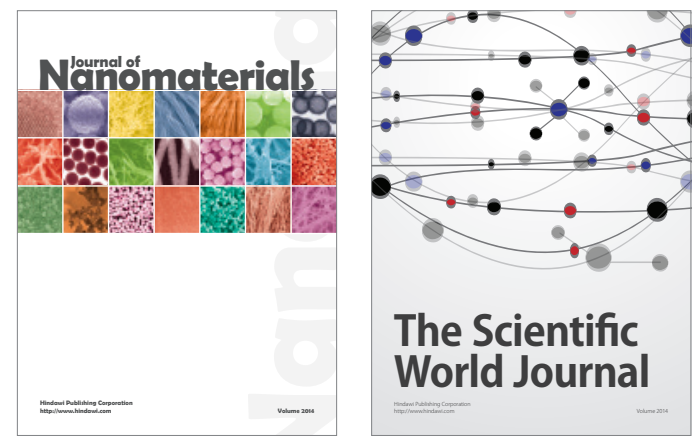

The Scientific World Journal
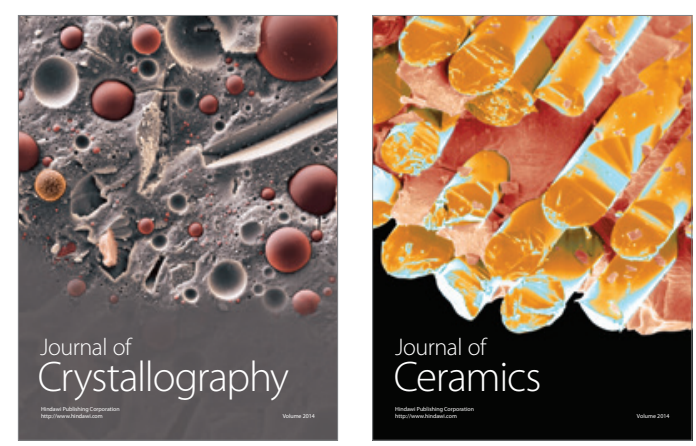
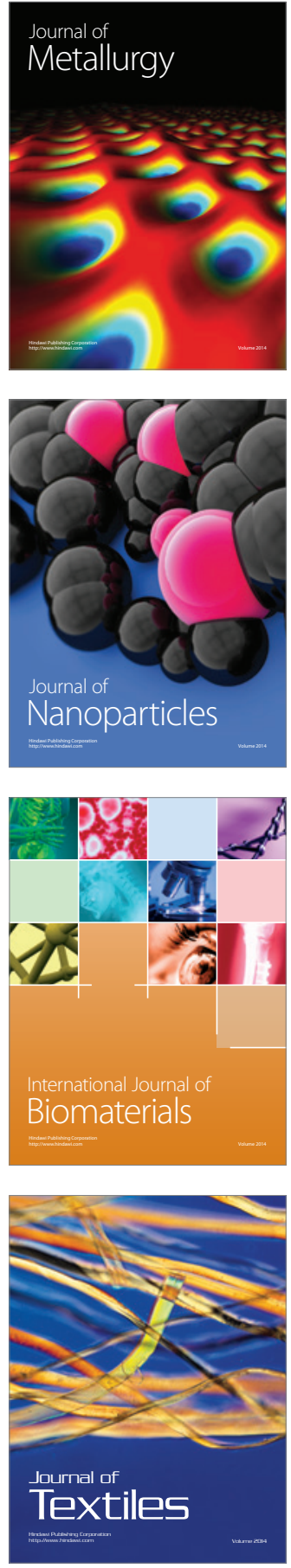